\title{
Measurement of physical activity and sedentary behavior in adolescents by accelerometer: a cross- sectional study
}

\author{
Atividade física e comportamento sedentário em adolescentes medidas por \\ acelerômetro: um estudo transversal
}

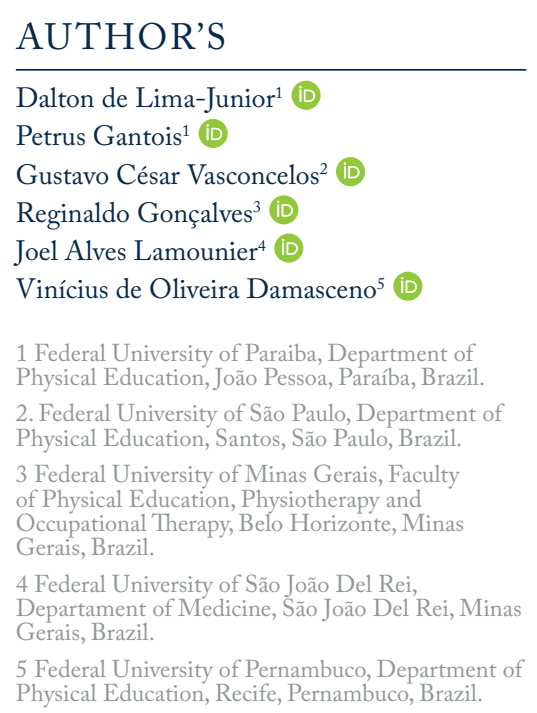

\section{CORRESPONDING}

Vinicius Oliveira Damasceno vinicius.damasceno@gmail.com Rua Aristides Muniz 121 apt 901, Boa Viagem, Recife, Pernambuco. Zip-code: 51020-150.

\section{DOI}

\subsection{0/rbafs.24e0104}

\section{(cc) BY-NC-SA}

This work is licensed under the Creative Commons Attribution-NonCommercial-ShareAlike 4.0 International License.

\begin{abstract}
The objective of this study was to analyze the level of physical activity and sedentary behavior (SB) in students from Minas Gerais, Brazil. It is a cross-sectional study with 153 participants of both sexes and had to be between 10 and 12 old. We carried out measurements of socioeconomic and anthropometric variables. Also, physical activity and sedentary behavior were measured using an accelerometer (MiniMitter, Actiheart ${ }^{\circledR}$ ). The accelerometer was fixed on the chest and the participants should remain with it for three days (Thursday, Friday, and Saturday). We categorized the data as SB

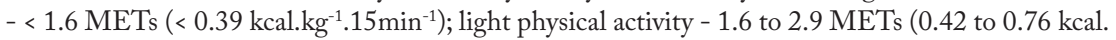
$\left.\mathrm{kg}^{-1} .15 \mathrm{~min}^{-1}\right)$. In the study, both sexes showed a low time of moderate and vigorous $(\sim 0.85$ hours/ day) activities. Higher times were recorded for light activity ( 2.6 hours/day) and SB ( 12.5 hours/ day) in both sexes. Also, boys spent greater time on a vigorous physical activity and lower time of $\mathrm{SB}$ in the three evaluated days $(\sim 1.3$ hours/day boys vs $\sim 0.4$ hours/day girls $)\left(\mathrm{p}=0.001 ; \mathrm{n}_{\mathrm{p}}{ }^{2}=0.42\right)$. However, the physical activity behavior was similar during weekdays and weekends $\left(\mathrm{p}=0.14 ; \mathrm{n}_{\mathrm{p}}{ }^{2}=\right.$ 0.078). We conclude that boys are more engaged than girls in physical activities in public schools of Minas Gerais, Brazil. However, SB is similar between them.
\end{abstract}

Keywords: Motor activity; Sedentary behavior; Adolescents.

\section{RESUMO}

O objetivo do estudo foi analisar o nivel de atividade física e comportamento sedentário (CS) em escolares. Trata-se de um estudo transversal com 153 escolares de 10 a 12 anos de ambos os sexos, de escolas públicas de São João Nepomuceno do estado de Minas Gerais, Brasil. Foi realizada a mensuração de variáveis socioeconômicas e antropométricas e a utilização de acelerômetro para medir o nivel atividade de física. $O$ acelerômetro foi fixado no peito dos participantes por um periodo de 3 dias (quinta, sexta e sábado). A partir disso os dados do acelerômetro foram definidos em CS - $1,6 \mathrm{METs}\left(<0,39 \mathrm{kcal}^{\mathrm{kg}} \mathrm{kg}^{-1} .15 \mathrm{~min}^{-1}\right)$; atividade física leve-1,6 a 2,9 METs $\left(0,42\right.$ a 0,76 kcal. $\left.\mathrm{kg}^{-1} .15 \mathrm{~min}^{-1}\right)$. No estudo, ambos os sexos apresentaram baixo tempo de atividades moderadas a vigorosas ( 0,85 horas/dia). O principal achado indicou um elevado tempo em atividade leves ( 2,6 horas/dia) e CS ( 12,5 horas/dia) em ambos os sexos. De acordo com o sexo, os meninos apresentaram mais tempo envolvidos em atividades físicas moderada a vigorosas e baixo CS nos três dias avaliados $\sim ~ 1,3$ horas/dia meninos e $\sim 0,4$ horas/dia meninas) $\left(p=0.001 ; n_{p}^{2}=0.42\right)$. Além disso, o comportamento da atividade física foi semelhante nos dias uiteis e finais de semana $\left(p=0.14 ; n_{p}^{2}=\right.$ 0.078). Concluímos que para os três dias avaliados, meninos apresentam maior tempo de envolvimento em atividades moderada a vigorosa, porém ambos os sexos com alto CS.

Palavras-chave: Atividade motora; Comportamento sedentário; Criança e adolescente.

\section{Introduction}

Physical activity among the adult population has been declining in the last decades, one of the main factors that are contributing is lifestyle changes during childhood and youth, mainly the lack of physical activity and high amounts of sedentary behavior (SB) during infancy and adolescence ${ }^{1}$. SB is described as activities in the sitting, inclining, or lying posture that presents values of energy expenditure close to that at rest. The most common activities that fit the definition of SB are watching television, playing video-games, and computer time ${ }^{2}$.

Investigating physical activity behavior is especially important in the pediatric population since even those 
children and adolescents who reach the current recommendations of physical activity for health benefits (i.e. minimum 60 min. $\mathrm{d}^{-1}$ of moderate-to-vigorous physical activity), it remains 23 hours per day for school, sleep, home-work, and discretionary time ${ }^{3}$. Recent investigations including Brazilian children and adolescents found that $>3$ hours per day of discretionary time are spent in screen time activities (i.e. watching television, video-games, and computer, so on) $)^{3}$. These results are in contrast to the recommendations of the World Health Organization (WHO), in which children and adolescents should not present more than two hours of screen time $^{4}$. Thereby, stimulating children and adolescents to practice physical activity might contribute to a healthier life during lifetime ${ }^{6}$. Children and adolescents that are physically inactive are more likely to present SB when compared to the most active ones ${ }^{3}$. So, physical activity lowers the risk factors that $\mathrm{SB}$ causes to health ${ }^{7}$.

Noteworthy, measuring physical activity alone is not enough to reduce the risks. SB might offset the benefits of physical activity, even the ones at high intensity ${ }^{8}$. For instance, a meta-analysis including over one million people showed that $>3$ hours/day spent watching television was associated with a higher rate of mortality regardless of physical activity pattern. Despite moderate physical activity (i.e. 60-75 minutes per day) appears to attenuate the risk, increased television watching time remains a risk independently ${ }^{9}$. Thereby, it is essential to measure both, physical activity and $\mathrm{SB}$, and analyze the risks altogether, but they should be considered as different constructs ${ }^{10}$. It is important to highlight that part of the recommendations on the physical activity level is based on the data required through questionnaires. In addition to measuring the level of physical activity, these questionnaires take into account distinct activities that influence the final scores. Because measurements in children and adolescents are challenging, research using accelerometers in that population point out in the same direction, however, the cost is high, especially for the developing countries ${ }^{11}$. The accelerometer is an objective method for physical activity and energy expenditure assessment, its measurement is predicted based on the acceleration of the members or other segments of the body ${ }^{12}$. Thus, that device can yield sound data and assist to identify lifestyle tendencies in different populations.

Considering the gradual decline in physical activity and increased SB during adolescence as a common epidemiological phenomenon across several countries ${ }^{6}$, monitoring physical activity levels in children and adolescents is fundamental for a better understanding about lifestyle as well as to develop public policies related to the health of the young population ${ }^{13}$. Furthermore, most existing evidence on physical activity and SB were obtained subjectively (self-reported) and pieces of evidence suggest a disagreement between subjective and objective methods, in which self-reported physical activity level tends to overestimate the time spent in moderate-vigorous activities and to underestimate the time spent in $\mathrm{SB}^{14}$. Thereby, the accelerometer is thought to provide more valid information about true physical activity behavior in the young population. Despite that, research using accelerometers in children and adolescents are still elusive, mostly due to complications in collecting data for this age group. Thus, this study aimed to analyze physical activity levels and SB in adolescents using accelerometer measures.

\section{Methods}

This is a descriptive study, with adolescent participants from a public school of an Urban area of Minas Gerais, Brazil. The participants were recruited in 10 schools, a total of 621 students between the fifth and seventh grade were enrolled in those schools in the year of 2012.

For the minimum sample size, a standard deviation (t-distribution) confidence level of $95 \%$ and a standard error of estimation of $5 \%$ was used. Thus, the sample size was 68 , including the average variable and the recommended daily energy use pattern in the pilot study $(1706 \mathrm{kcal} \pm 380 \mathrm{kcal})$. However, adopting an estimated loss of $30 \%$ to $70 \%$, a final sample reached 153 participants aging from 10 to 12 years old of both sexes. The research was conducted by professors and students of physical education who received instruction on how to handle the accelerometer.

As the inclusion criteria, the participants had to be between 10 and 12 years old, healthy and enrolled in any public school during the morning or afternoon period. Participants would be excluded if three days were not collected or any errors in accelerometer measurements were not valid (error $<1 \mathrm{~h}$ ). All the volunteers gave assent to the study and his parents/guardians signed the written informed consent to participate in the study. Losses from the study were considered as students who refused to be part of the study. The study was approved by the Research Ethical Committee of the Federal University of Minas Gerais (UFMG), No 0396.0.203.000.10. 
Regarding the demographic information of the participants, it was collected in an economic class questionnaire based on the National Association of Market Research Companies (ABEP) guidelines ${ }^{15}$. Moreover, an interview with the participants and their parents was conducted with questions developed by the authors to evaluate physical activities (i.e. displacement to school, physical activity level) and SB (i.e. sleeping time and screen time) in a daily basis.

Anthropometric measurements were taken for each child in a private room. The measurements of weight and skinfold were performed as well as the waist, hip, and abdomen circumferences. During the assessment, a socio-demographic questionnaire was filled in by the parents, also an informative paper about the appropriate use of the accelerometer was given.

Bodyweight was measured using a digital scale (Seca 877 , Australia) with a maximum capacity of $150 \mathrm{~kg}$ and accuracy of $0.1 \mathrm{~kg}$, whereas height was measured using a stadiometer (Alturaexata, Brazil) measuring from 1 to $213 \mathrm{~cm}$ with an accuracy of $0.1 \mathrm{~cm}$.

Circumferences of the waist, abdomen, and hip were measured using a tape (Sanny, Brazil). Skinfolds of the triceps, abdomen, subscapular, and the medial calf were measured by an adipometer (Lange Skinfold Caliper $\left.{ }^{\circledR}\right)$, ranging from 0 to $60 \mathrm{~mm}$ with an accuracy of $1 \mathrm{~mm}$. The measurements were carried out by a professional with more than 10 years of experience and according to the ISAK norms.

The accelerometer Actibeart ${ }^{\circledR}$ developed by MiniMitter was used in this study. This device is valid (ICC = $0.99, \mathrm{P}=0.001)^{16}$ and reliable $(\mathrm{ICC}=0.99, \mathrm{P}=0.001)^{16}$ for physical activity assessment in different populations ${ }^{17}$. Each device weighs $8 \mathrm{~g}$, lengths $7 \mathrm{~mm}$, and has a diameter of $33 \mathrm{~mm}$ with an internal motion sensor that is sensitive to acceleration in the horizontal and vertical axis. In addition, the device measures heart rate, energy expenditure, and electrocardiographic activity in a pre-determined time (15s; 30s; or $1 \mathrm{~min})$. Data were stored in a flash drive and read by the software developed by MiniMitter version 2.2 for windows.

It was explained to the participants how to take off and put on the device during the periods of the day involving water (bath, pool, waterfall, and so on). Before the device fixation, the local was cleaned up with alcohol and the electrode Becton Dickson (BD) was put on for electromyographic readings. The accelerometer was fixed on the chest and the participants should remain with it for 3 days (Thursday, Friday, and Saturday). On the fourth day (Sunday), one member of the research team went to the home of the participant to collect the device. After that, we categorized the data as SB $<1.6$ METs (<0.39 kcal. $\left.\mathrm{kg}^{-1} .15 \mathrm{~min}^{-1}\right)$; light -1.6 a 2.9 METs (0.42 a $\left.0.76 \mathrm{kcal}_{\mathrm{kg}} \mathrm{k}^{-1} .15 \mathrm{~min}^{-1}\right)$; defined as: $\bmod -$

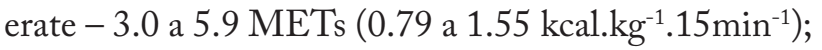
vigorous $>6.0 \mathrm{METs}\left(>1.58 \mathrm{kcal}^{\mathrm{kg}} \mathrm{kg}^{-1} .15 \mathrm{~min}^{-1}\right)^{3,4}$. The basal metabolic rate was calculated by the equation proposed by Scholfield (1985) ${ }^{18}$ and summed up to the value yielded by the accelerometer. Considering model corrections for daily energy expenditure, a routine was built on the Matlab using Zakeri et al. equation ${ }^{19}$.

All data were described as mean and standard deviation. For verifying the distribution Kolmogorov-Smirnov test was applied. Three-way ANOVA was utilized to compare physical activity vs sex vs day, in case of significance, the Bonferroni post-hoc was used. All analyses were performed using SPSS ${ }^{\oplus}$ for $W_{\text {indows }}$ version $20.0, I B M^{\circledast}$. The alpha value adopted was $5 \%$ for all analyses.

\section{Results}

The participants were 153 children and adolescents between 10 and 12 years old. The sample was composed by 84 girls, and 69 boys (11.02 \pm 0.81 years, 44.62 $\pm 10.58 \mathrm{~kg} 1.51 \pm 0.08 \mathrm{~m}, 24.98 \pm 9.30 \%$ fat mass, and $19.48 \pm 3.66 \mathrm{Kg} / \mathrm{m}^{2}$ ) - Table 1 . Tables 2 and 3 show a description of the sample in terms of socioeconomic, auto perception, and parents' perception of weight and physical activity. More than $50 \%$ of the participants belonged to the classes C and D $(28.1 \%$ and $32.7 \%$, respectively) of socioeconomic status. Nearly $50 \%$ of the adolescents find themselves as having an ideal weight and $\sim 61 \%$ believe they are in good physical activity levels. These results coincide with the parents' perception of the level of physical activity of their children. Table 2 displays that $\sim 60 \%$ of parents believe that their children are at good levels of physical activity and most of them reported that TV time varies between 1 to $2 \mathrm{~h} /$ day and 2 to $3 \mathrm{~h} /$ day (20.3\% and $24.8 \%$, respectively).

Table 3 shows a three-way ANOVA comparison of the sample regarding the physical activity vs sex vs day. A three-way ANOVA showed no difference between sex on SB time (min/day). Regarding physical activity, the boys presented more time in vigorous activities $(\sim$ 1.3 hours/day boy vs $\sim 0.4$ hours/day girl) $(p=0.001$; $\mathrm{n}_{\mathrm{p}}^{2}=0.42$ ) when compared to girls. Also, no difference was found in total time physical activity when comparing weekdays and weekends $\left(\mathrm{p}=0.14 ; \mathrm{n}_{\mathrm{p}}^{2}=0.078\right)$. 
Table 1 - Anthropometric characteristics of the participants. Minas Gerais, Brazil, 2012 ( $\mathrm{n}=153$ )

\begin{tabular}{lcccccc}
\hline & Mean & SD & Minimum & Maximum & \multicolumn{2}{c}{ CI 95\% } \\
\hline Age (years) & 11.02 & 0.81 & 10.00 & 12.00 & 10.89 & 11.15 \\
$\begin{array}{l}\text { Weight at birth } \\
\text { (kg) }\end{array}$ & 3.39 & 0.61 & 1.70 & 4.60 & 3.28 & 3.50 \\
$\begin{array}{l}\text { Height at birth } \\
\text { (cm) }\end{array}$ & 48.58 & 3.25 & 35.00 & 60.00 & 47.94 & 49.17 \\
Weight $(\mathrm{kg})$ & 44.62 & 10.58 & 26.60 & 80.40 & 42.8 & 46.3 \\
Height $(\mathrm{m})$ & 1.51 & 0.08 & 1.34 & 1.70 & 1.49 & 1.52 \\
BMI (kg/m²) & 19.48 & 3.66 & 13.45 & 31.41 & 18.90 & 20.05 \\
Fat Mass $(\%)$ & 24.98 & 9.30 & 9.09 & 55.39 & 23.40 & 26.40 \\
\hline
\end{tabular}

Table 2 - Characteristics of the participants obtained by interviewing the adolescents. Minas Gerais, Brazil, 2012 ( $n=153$ )

\begin{tabular}{lcc}
\hline & $\mathrm{n}$ & $\%$ \\
\hline Sex & & \\
Boy & 69 & 43.4 \\
Girl & 84 & 52.8 \\
Do not know & 06 & 3.8 \\
Socioeconomic class & & \\
A & 06 & 3.9 \\
B & 31 & 20.3 \\
C & 43 & 28.1 \\
D & 50 & 32.7 \\
E & 23 & 15.0 \\
Auto perception of weight in adolescents & & \\
Obese & 03 & 2.0 \\
Overweight & 23 & 15.0 \\
Normal & 76 & 49.7 \\
Underweight & 03 & 2.0 \\
Do not know & 48 & 31.4 \\
Auto perception of physical activity by adolescents & & \\
Highly active/Extremely Active & 94 & 61.4 \\
Low active/Sedentary & 27 & 17.7 \\
Did not know & 32 & 20.9 \\
\hline
\end{tabular}

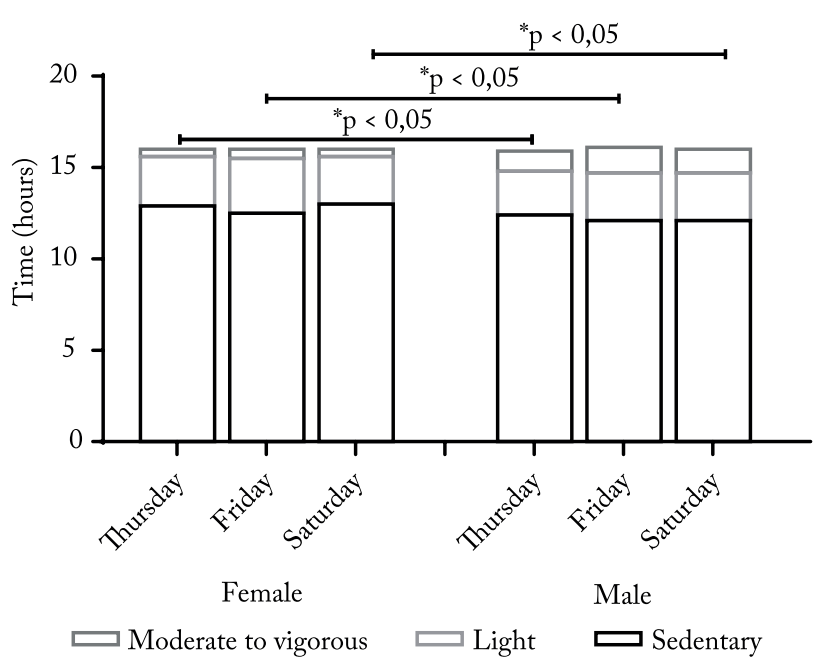

Figure 1 - Hours of physical activity according to sex and day * moderate to vigorous physical activity different between sexes
Table 3 - Characteristics of the participants obtained by interviewing the parents. Minas Gerais, Brazil, 2012 ( $n=153)$

\begin{tabular}{|c|c|c|}
\hline & $\mathrm{n}$ & $\%$ \\
\hline \multicolumn{3}{|l|}{ Displacement to school } \\
\hline Walk & 53 & 34.6 \\
\hline Bicycle & 02 & 1.3 \\
\hline Public transportation & 30 & 29.4 \\
\hline Personal vehicle & 19 & 12.4 \\
\hline Do not know & 49 & 32.0 \\
\hline \multicolumn{3}{|c|}{ Moderate to vigorous physical activity outside school } \\
\hline Yes & 61 & 39.9 \\
\hline No & 44 & 28.8 \\
\hline Do not know & 48 & 31.3 \\
\hline \multicolumn{3}{|c|}{ Parents perception of physical activity in adolescent: } \\
\hline Highly active/ extremely active & 94 & 61.4 \\
\hline Low active/ sedentary & 27 & 17.7 \\
\hline Do not know & 32 & 20.9 \\
\hline \multicolumn{3}{|c|}{ Parents perception of TV hours/day in adolescent: } \\
\hline$<1 \mathrm{~h} /$ day & 10 & 6.5 \\
\hline 1 to $2 \mathrm{~h} /$ day & 31 & 20.3 \\
\hline 2 to $3 \mathrm{~h} /$ day & 38 & 24.8 \\
\hline 3 to $4 \mathrm{~h} /$ day & 17 & 11.1 \\
\hline 4 to $5 \mathrm{~h} /$ day & 15 & 09.8 \\
\hline$+5 \mathrm{~h} /$ day & 10 & 06.5 \\
\hline Do not know & 32 & 20.9 \\
\hline \multicolumn{3}{|c|}{ Parents perception of sleeping time per day in adolescent: } \\
\hline Less than 7 hours & 08 & 5.2 \\
\hline 7 to 10 hours & 97 & 63.4 \\
\hline More than 10 hours & 16 & 10.5 \\
\hline Do not know & 32 & 20.9 \\
\hline \multicolumn{3}{|c|}{ Parents perception of weight in adolescent } \\
\hline Underweight & 03 & 2.0 \\
\hline Normal & 76 & 49.7 \\
\hline Overweight & 23 & 15.0 \\
\hline Obese & 03 & 2.0 \\
\hline Do not know & 48 & 31.3 \\
\hline
\end{tabular}

\section{Discussion}

The main findings of our study were that our participants spent lower time in moderate to vigorous physical activity with the difference between sex. Girls engage in less moderate-vigorous activities than boys in all the three days and also spent more time in SB. Importantly, even the boys that achieved the current recommendations of physical activity ${ }^{4}$, they still engage in high amounts of SB as shown in the present study (Table 3). In all the investigated days, both sexes presented several hours spent in SB. Specifically, parents were asked about the hours spent by their children watching television. Only $6.5 \%$ of the adolescents spent less than 1 hour per day on screen time, 20.3\% between 1 and 
2 hours per day, and $52 \%$ more than 2 hours per day of screen time (Table 3). Those results are a warning about the health risks of SB for young people. Furthermore, most of the adolescents consider themselves as highly to extreme physically active (61.4\%), and only $17.7 \%$ believe they are lowly physically active or sedentary. The same values were observed for the parents. Conversely, objective measurement using accelerometer data shows that our participants reached out a value of 0.85 hours per day in moderate to vigorous physical activity. These disagreements between self-reported and accelerometer data in our study reinforce the need for objective measurements to determine physical activity behavior in the young population.

Sex differences in physical activity behavior have been commonly reported in the literature ${ }^{20}$ and the present study confirms those findings at all days investigated. Boys reached 1.30 hours per day of moderate to vigorous physical activity, whereas girls only 0.47 . According to WHO recommendations for physical activity ${ }^{4}$, children and adolescents should perform at least 60 minutes of physical activity in moderate to vigorous intensity in at least five days during the week. Thus, our findings are a warning for children and adolescents since the girls does not achieve even half of the minimum recommended of moderate to vigorous physical activity, and boys are only a few minutes above the threshold. In the US, a longitudinal population-based study using accelerometer from 9 to 15 years old found that at nine years almost all children reached the current recommendations of 60 minutes of moderate-vigorous physical activity. On the other hand, at 15 years old only $31 \%$ met the guidelines on weekdays and this prevalence decreases to $17 \%$ on weekends ${ }^{21}$. In the same study, a decrease of $12.5 \%$ in moderate-vigorous physical activity per year was observed and a greater decline was found in girls (13.1\%) than in boys (11.9\%). Importantly, despite the difference found in the present study between boys and girls regarding the hours spent in moderate-to-vigorous physical activity (Figure 1), both of them are far from the limits of the values considered accepted to a healthy lifestyle.

In our study, the mean time monitoring the participants was 14 hours/day, and sleeping time was set as 8 hours/day. Considering the time that the adolescents remained awake, more than 12 hours/day were spent in SB according to the accelerometer data (Figure 1). In a cohort study including school-age adolescents from Pelotas, Rio Grande do Sul, Brazil, they showed that almost
$80 \%$ of their waking hours are spent in $\mathrm{SB}^{6}$. As adolescents spend more hours of their free time on screen time activities $^{3}$, it could be expected that more time would be spent in SB on the weekends. Both, boys and girls spent similar amounts of sedentary time across all the investigated days. A systematic review ${ }^{5}$ indicated that the prevalence of SB has two main factors: first, it is related to a long time spent on screen time as video-games and computers; second, it is exclusive to another kind of screen time, as television. Results from Pesquisa Nacional de Saúde Escolar PeNSE (2009)22, showed that 79.5\% of school-age children watched television two or more hours per day. This percentage ranged from 74 to $83 \%$ in Boa Vista and Cuiabá, Brazil respectively. According to the parents, our participants spent more than one-fourth of their awake hours watching television. Taken together, these data highlight that Brazilian school-age children and adolescents present prolonged screen time. In a prospective US study, prolonged television time was related to all-cause of mortality and a two-fold increased risk of cardiovascular diseases ${ }^{23}$. Another population-based study in Europe showed that spending more than two hours watching television is a common practice in adolescent ${ }^{8}$. However, WHO guidelines suggest that this practice might be harmful ${ }^{4}$. Besides, Canadian guidelines state that for health benefits, children and adolescents should minimize the time they spend in SB each day. These recommendations should be taken seriously, even for those who are above the current recommendations for physical activity. A study including 2200 European adolescents have shown that excessive TV viewing is associated with obesity, even adjusting by physical activity levels using accelerometer data. Also, a recent meta-analysis found that even for those who participate in 60-75 minutes of physical activity per day do not eliminate the increased risks of mortality associated with high television viewing time 9 . Although male adolescents in our study met the recommendations of physical activity, they spent more than 12 hours in SB, suggesting that they do not eliminate the increased risks of mortality. More worrying, girls present similar SB, but they do not meet the minimum values of physical activity for health benefits.

Considering that our participants are school-age population, regardless of any differences between school and after school, the school setting appears to promote high hours in $\mathrm{SB}^{24,25}$. In Brazil, public school-time consists of five 45 -min classes with one 15 min recess between the third and fourth classes, thus, time spent in school represents almost a third of an adolescent's day 
and more than two hours of this time is spent in SB (i.e. sitting) ${ }^{26}$. Thereby, reducing SB in the classroom should be encouraged. A recent body of investigation has begun to explore the adoption of "standing desks" strategies, which can be raised in the classroom to reduce the time that school children spend sitting in school. In a crossover study including US school children, an increase in caloric expenditure standing at a nontraditional standing desk $(1.36 \pm 0.20 \mathrm{kcal} / \mathrm{min})$ compared to traditional sitting behavior $(1.02 \pm 0.22 \mathrm{kcal} / \mathrm{min})$ was found ${ }^{27}$. In this same study, authors observed an expenditure caloric increase of $~ 114 \mathrm{kcal} /$ day by using a standing desk when compared to the sitting condition, it could be a great way to reduce a positive energy balance, considering the high time spent in the classroom. Also, after a fivemonth period, a similarly increased caloric expenditure was found by using a standing desk for two hours/day (17 to $25.7 \%$ greater caloric expenditure) compare to sitting condition ${ }^{1}$. Despite pieces of evidence demonstrating a positive impact on energy expenditure and reducing the sitting time in school environment ${ }^{28}$, long term efficacy trials are needed to determine the impact of this strategy on physical activity behavior and health outcomes in the young population.

According to parents' perception, $30 \%$ of our participants did not perform moderate or vigorous physical activity outside of school. Noteworthy, this value might be underestimated since $31.3 \%$ of parents did not know the answer. A recent systematic review stated that 60 minutes or more of physical activity could be accumulated in the school environment during physical education classes, sports, as well as before and after classrooms ${ }^{29}$. Also, a higher physical activity level might indicate a lower time spent in $\mathrm{SB}^{30}$. Importantly, school physical education has the potential to provide regular physical activity to the majority of public-school children, since physical education classes are an integral part of the Brazilian educational system ${ }^{25}$. Thereby, schools should be considered the primary societal institution with the responsibility for promoting physical activity in young people ${ }^{31}$.

From a practical perspective, our results have important implications for public health policies and physical activity counseling. Increased hours spent in $\mathrm{SB}$ and the low engagement in moderate to vigorous physical activity experienced by our participants should be analyzed carefully. Decreasing moderate-vigorous physical activity and increasing the time spent in SB from childhood to adolescence is a common trend across several countries ${ }^{20}$. Thereby, a multi-dimensional approach should be encouraged to limit recreational screen time to no more than two hours per day, stimulate the break of prolonged SB, mostly in a classroom (i.e. sitting time), and develop strategies that increase the motivation to engage in moderate-vigorous physical activities aimed at reducing the risks associated with health. To achieve those goals, the interaction between family, school, and government environments should be considered.

Our study presents some limitations. Sleep time was not measured, and we independently considered eight hours of sleep. Also, we measured three days of physical activity, the ideal setting would be five days to understand physical activity behavior. However, none of the participants report any sleep disorder and three days of measurements were enough to indicate behavior differences.

The monitoring of physical activity levels and SB among adolescents is fundamental to understand the determinant factors and changes in the lifestyle of young people. Increasing the physical activity practice as recommended and reducing the SB in this age group is beneficial and might contribute to healthy and active adult life. The present results may contribute to the scientific community and the general population in understanding the current physical activity and $\mathrm{SB}$ of adolescents and give directions on policies that benefit this population.

\section{Conflict of interest}

The authors declare no conflict of interest.

\section{Funding}

We are thankful for all the participants on their engagement in this study, the Coordination of Improvement of Higher Education Personnel (CAPES/Brazil) for the scholarships conceded to Lima-Junior D, Gantois P, and Vasconcelos GC (doctoral).

\section{Author's contribution}

Lima-Junior D, developed the theory and wrote and performed the analyses of the manuscript. Gantois P, wrote and performed the analyses of the manuscript. Vasconcelos GC, wrote and performed the analyses of the manuscript. Gonçalves R, discussed the results and contributed to the final manuscript. Lamounier JA, discussed the results and contributed to the final manuscript. Damasceno VO, wrote the manuscript, discussed the results and contributed to the final manuscript, and collected data.

\section{Acknowledgements}

We would like to express thanks to all the participants for their 
engagement in this study and the English language support by Julie Pessoa and Elizabeth Schilpp.

\section{References}

1. Benden ME, Blake JJ, Wendel ML, Huber Junior JC. The impact of stand-biased desks in classrooms on calorie expenditure in children. Am J Public Health. 2011;101(8):1433-6.

2. Farias Júnior JC. (In) Atividade física e comportamentosedentário: estamos caminhando para umamudança de paradigma? Rev Bras Ativ Fís Saúde. 2011;16(4):279-80

3. Tremblay MS, LeBlanc AG, Kho ME, Saunders TJ, Larouche $\mathrm{R}$, Colley RC, et al. Systematic review of sedentary behaviour and health indicators in school-aged children and youth. Int J Behav Nutr Phys Act. 2011;8:98.

4. Organization WH. Global recommendations on physical activity for health. 2010.

5. Friedrich RR, Polet JP, Schuch I, Wagner MB. Efeito dos programas de intervenção no âmbito escolar para reduzir o tempo gasto em frente a telas: uma meta-análise. J Pediatr. 2014;90:232-41.

6. Dumith SC, Gigante DP, Domingues MR, Kohl III HW. Physical activity change during adolescence: a systematic review and a pooled analysis. Int J Epidemiol. 2011;40(3):685-98.

7. Hallal PC, Victora CG, Wells JC, Lima RC. Physical inactivity: prevalence and associated variables in Brazilian adults. Med Sci Sports Exerc. 2003;35(11):1894-900.

8. Owen N, Healy GN, Matthews CE, Dunstan DW. Too much sitting: the population-health science of sedentary behavior. Exerc Sport Sci Rev. 2010;38(3):105.

9. Ekelund U, Steene-Johannessen J, Brown WJ, Fagerland MW, Owen N, Powell KE, et al. Does physical activity attenuate, or even eliminate, the detrimental association of sitting time with mortality? A harmonised meta-analysis of data from more than 1 million men and women. The Lancet. 2016;388(10051):1302-10.

10. Ortega FB, Konstabel K, Pasquali E, RuizJR,Hurtig-Wennlöf A, Mäestu J, et al. Objectively measured physical activity and sedentary time during childhood, adolescence and young adulthood: a cohort study. PloS One. 2013;8(4):e60871.

11. Hallal PC, Knuth AG, Cruz DKA, Mendes MI, Malta DC. Prática de atividade física em adolescentes brasileiros. Ciên Saúde Coletiva. 2010;15:3035-42.

12. Graauw SM, Groot JF, van Brussel M, Streur MF, Takken T. Review of prediction models to estimate activity-related energy expenditure in children and adolescents. Int J Pediatr. 2010;2010:489304.

13. Troiano RP, McClain JJ, Brychta RJ, Chen KY. Evolution of accelerometer methods for physical activity research. Br J Sports Med. 2014;48(13):1019-23.

14. Dyrstad SM, Hansen BH, Holme IM, Anderssen SA. Comparison of self-reported versus accelerometer-measured physical activity. Med Sci Sports Exerc. 2014;46(1):99-106.

15. Associação Brasileira de Empresas de Pesquisa. Critério de Classificação Econômica Brasil. Associação Brasileira de Empresas de Pesquisa. São Paulo; 2016.
16. Brage S, Brage N, Franks PW, Ekelund U, Wareham NJ. Reliability and validity of the combined heart rate and movement sensor Actiheart. Eur J Clin Nutr. 2005;59(4):561.

17. Freedson P, Pober D, Janz KF. Calibration of accelerometer output for children. Med Sci Sports Exerc. 2005;37(11 Suppl):S523-30.

18. Schofield W. Predicting basal metabolic rate, new standards and review of previous work. Hum Nutr Clin Nutr. 1985;39:5-41.

19. Zakeri IF, Adolph AL, Puyau MR, Vohra FA, Butte NF. Multivariate adaptive regression splines models for the prediction of energy expenditure in children and adolescents. J Appl Physiol (1985). 2010;108(1):128-36.

20. Cooper AR, Goodman A, Page AS, Sherar LB, Esliger DW, van Sluijs EM, et al. Objectively measured physical activity and sedentary time in youth: the International children's accelerometry database (ICAD). Int J Behav Nutr Phys Act. 2015;12(1):113.

21. Nader PR, Bradley RH, Houts RM, McRitchie SL, O'Brien M. Moderate-to-vigorous physical activity from ages 9 to 15 years. JAMA. 2008;300(3):295-305.

22. Penna G. Pesquisa Nacional de Saúde do Escolar (PeNSE). Cien Saude Colet. 2010;15:3006.

23. Matthews CE, George SM, Moore SC, Bowles HR, Blair A, Park Y, et al. Amount of time spent in sedentary behaviors and cause-specific mortality in US adults. Am J Clin Nutr. 2012;95(2):437-45.

24. Harrington DM, Dowd KP, Bourke AK, Donnelly AE. Cross-sectional analysis of levels and patterns of objectively measured sedentary time in adolescent females. Int J Behav Nutr Phys Act. 2011;8(1):120.

25. Silva DR, Minderico CS, Pinto F, Collings PJ, Cyrino ES, Sardinha LB. Impact of a classroom standing desk intervention on daily objectively measured sedentary behavior and physical activity in youth. J Sci Med Sport. 2018.

26. Costa BG, Silva KS, George AM, de Assis MAA. Sedentary behavior during school-time: Sociodemographic, weight status, physical education class, and school performance correlates in Brazilian schoolchildren. J Sci Med Sport. 2017;20(1):70-4.

27. Reiff C, Marlatt K, Dengel DR. Difference in caloric expenditure in sitting versus standing desks. J Phys Act Health. 2012;9(7):1009-11.

28. Sherry AP, Pearson N, Clemes SA. The effects of standing desks within the school classroom: A systematic review. Prev Med Rep. 2016;3:338-47.

29. Strong WB, Malina RM, Blimkie CJ, Daniels SR, Dishman RK, Gutin B, et al. Evidence based physical activity for school-age youth. J Pediatr. 2005;146(6):732-7.

30. Cawley J, Frisvold D, Meyerhoefer C. The impact of physical education on obesity among elementary school children. J Health Econ. 2013;32(4):743-55.

31. Sallis JF, Johnson MF, Calfas KJ, Caparosa S, Nichols JF. Assessing perceived physical environmental variables that may influence physical activity. Res Q Exerc Sport. 1997;68(4):345-51.

Received: 20/10/2018

Approved: 03/06/2020

Quote this article as:

Lima-Junior D, Gantois P, Vasconcelos GC, Gonçalves R, Lamounier JA, Damasceno VO. Measurement of Physical Activity and Sedentary Behavior in Adolescents by accelerometer: a cross-sectional study. Rev Bras Ativ Fis Saúde. 2019;24:e0104. DOI: 10.12820/rbafs.24e0104 